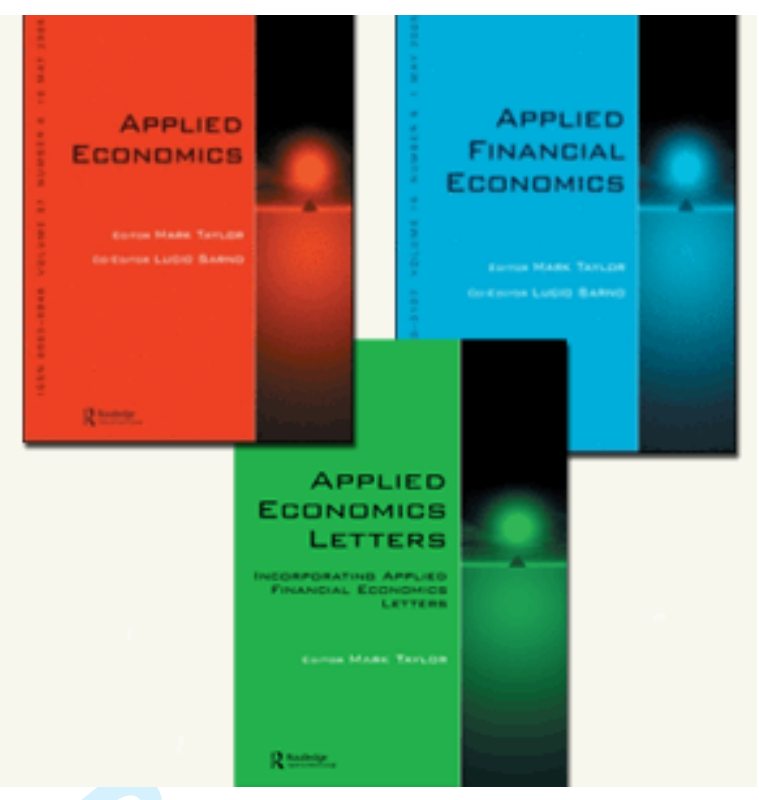

\title{
Does drinking affect long-term sickness absence? A sample selection approach correcting for employment and accounting for drinking history
}

\begin{tabular}{|r|l|}
\hline Journal: & Applied Economics \\
\hline Manuscript ID: & APE-2010-0173 \\
\hline Journal Selection: & Applied Economics \\
\hline Date Submitted by the & 07-Apr-2010 \\
\hline Complete List of Authors: & $\begin{array}{l}\text { Jarl, Johan; Lund University / Region Skåne, Center for Primary } \\
\text { Health Care Research; Lund University, Health Economics \& } \\
\text { Management } \\
\text { Gerdtham, Ulf-G.; Lund University / Region Skåne, Center for } \\
\text { Primary Health Care Research; Lund University, Health Economics \& } \\
\text { Management; Lund University, Economics }\end{array}$ \\
\hline JEL Code: & $\begin{array}{l}\text { J21 - Labor Force and Employment, Size, and Structure < J2 - Time } \\
\text { Allocation, Work Behavior, and Employment Determination/Creation } \\
<\text { J - Labor and Demographic Economics, I12 - Health Production: } \\
\text { Nutrition, Mortality, Morbidity, Disability, etc. < I1 - Health < I - } \\
\text { Health, Education, and Welfare }\end{array}$ \\
\hline Keywords: & \begin{tabular}{l} 
\\
\hline
\end{tabular} \\
\hline
\end{tabular}




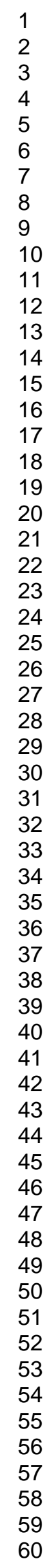

\section{S) ScholaroNE" \\ Manuscript Central}




\section{Does drinking affect long-term sickness absence? A sample selection approach correcting for employment and accounting for drinking history}

Running head: Alcohol and long-term sickness absence

J. Jarl ${ }^{\mathrm{a}, \mathrm{b},{ }^{*}}$ and U-G. Gerdtham ${ }^{\mathrm{a}, \mathrm{b}, \mathrm{c}}$

${ }^{a}$ Health Economics \& Management, Institute of Economic Research, Lund University, S22100 Lund, Sweden

${ }^{\mathrm{b}}$ Center for Primary Health Care Research, Lund University/Region Skåne, S-20502 Malmö, Sweden

${ }^{\mathrm{c}}$ Economics Department, Lund University, S-22100 Lund, Sweden

* Corresponding author: Johan Jarl, Division of Health Economics, Dept. of Clinical Science, Lund University, Malmö University Hospital, SE-205 02 Malmö, Sweden, E-mail:

johan.jarl@med.lu.se

This article studies the effect of alcohol consumption on the probability of long-term sicknessrelated absenteeism for women. Using Swedish matched survey and register data, we apply sample selection models to correct for non-random sampling into paid employment. There are three main findings of the study. First, diverging from the most prevalent consumption group (long-term light drinkers) is associated with an increased probability of long-term sickness, ranging from $10 \%$ for long-term heavy drinkers to $18 \%$ for former drinkers. Second, controlling for former consumption errors (especially former drinker and former abstainer errors) and sample selection into employment are important for unbiased, consistent estimations. Third, by predicting the effect of changes in consumption on long-term sicknessrelated absence, we find that alcohol only explains a small part of the overall picture of longterm sickness-related absenteeism. Notwithstanding this fact, long-term sickness-related absenteeism due to alcohol adds up to substantial productivity loss for society. Our conclusion is that the commonly found U-shaped relationship between current alcohol consumption and labour market outcomes remains for women, after controlling for past consumption and selection effects. A change in consumption level increases probability of long-term sicknessrelated absence, compared to individuals with constant consumption levels. 


\section{Introduction}

Sweden experienced a rapid increase in sickness-related absence ${ }^{1}$ from 1998 to 2003, and although the trend shifted in 2004, Sweden continues to experience one of the highest absence rates in Western Europe. In fact, in 2004, the rate of absences was about twice as high in Sweden as compared to the EU-15 countries (4\% versus 2\%) (Försäkringskassan, 2005). This was costly to Swedish society and has attracted significant attention and study regarding its causes. From an international perspective, the causes of absence have received attention in the context of efforts to reduce these rates for the purposes of improving public health and decreasing health costs (HSE, 2004). Several potential causes have been studied, including shift work (Tüchsen et al., 2008), moral hazard (Johansson and Palme, 2005), contractual arrangements (Barmby et al.,. 2004), work stress (Vasse et al., 1998) and health-related behaviours (Christensen et al., 2007).

Focusing on health-related behaviours in general and alcohol consumption in particular is considered important as alcohol-related absence constitutes a significant part of the societal cost of alcohol. For example did a recent Swedish study estimate alcohol-related absence to SEK 4.3 billion for the year 2002, after subtracting reductions from beneficial health effects (Jarl et al., 2008). This figure constitutes over $21 \%$ of the total cost to the Swedish society from alcohol. $73 \%$ of the burden of absence is due to long-term absence (defined as longer than 14 days). Alcohol-related absence is thus a substantial burden on the society which would explain policy makers' interest in ways to reduce the absence rates.

It has been difficult to arrive at any final conclusions about the effect of alcohol on absence rates in prior research. In a review regarding absence, psychiatric disorders and alcohol,

\footnotetext{
${ }^{1}$ From here on only "absence".
} 
Hensing and Wahlström (2004) conclude that there is insufficient evidence that alcohol affects absence. The studies reviewed, however, showed that individuals diagnosed with alcohol dependence or abuse suffer more and/or longer periods of absence (Hensing and Wahlström, 2004). Studies focusing on high alcohol consumption did not show any conclusive results, probably due to different definitions of both high alcohol consumption and absence. Some studies reported that women who do not consume alcohol are at increased risk of absence (Hensing and Wahlström, 2004); this result is not surprising given the negative outcomes associated with abstention that are commonly found in studies on alcohol (e.g. Andréasson, 1998; Peters, 2004).

In more recent studies, there is some evidence of the effect of alcohol on absence. For example, it has been shown that the risk of short-term absenteeism is increased the day after alcohol consumption (McFarlin and Fals-Stewart, 2002). A Finnish study using micro-data found a positive association between the level of consumption and absence (Johansson et al., 2009). Cunradi et al. (2005) showed that short-term absenteeism was associated with several measures of problem drinking in a sample of urban transit operators, while Tómasson et al. (2004) found no effect of problem drinking on sick leave in a female working sample. Roche et al. (2008) found that risky alcohol consumption (compared to low-risk), increases both selfreported alcohol-related absenteeism and overall illness/injury absenteeism. The prevalence of absenteeism was higher with higher risk consumption as well as more frequent, risky consumption. This is the only study that incorporates pattern as well as the level of consumption. Norström (2006), in a time series analysis of aggregated alcohol consumption on absence, found that a one litre increase in consumption is associated with a $13 \%$ increase in absence among men. No significant effects were found among women. These results were later repeated in a similar study in Norway (Norström and Synnøve Moan, 2009). 
Two recent studies have employed alcohol groups based on the level of consumption when studying the effect on absenteeism. Based on average weekly levels, Vahtera et al. (2002) found that, compared to light drinkers, there was an increased risk of absence for former drinkers, heavy drinkers, and those who abstain from drinking. They concluded that the Ushaped relationship could not be explained by confounding psychosocial factors or the "former drinker error" (i.e., including former drinkers in the abstainer group). A Danish study investigated the effect of health behaviours on long-term sickness (Christensen et al. 2007). Two analyses were conducted wherein the alcohol variable was first divided into heavy versus non-heavy drinkers, and second into non-drinkers, moderate drinkers and heavy drinkers, defined by weekly level. No association between alcohol and long-term absence was found. It should be noted that although the authors controlled for former smoking in their regressions, they did not control for former drinking.

This article analyses the effect of alcohol consumption on sickness absence. There are several significant contributions of the study. First, focus is on the rarely studied long-term absence, which is due to the fact that many of the detrimental health effects associated with alcohol are chronic and have relatively long recovery processes. Also, long-term absence was shown in the recent Swedish cost of alcohol study to amount to $73 \%$ of the total absence cost (Jarl et $a l ., 2008)$. Second, the effect of drinking history is controlled for, as it is expected to play a key role in long-term absenteeism, i.e. the long-term effect of alcohol consumption. Third, a sample selection model is used that correct for the effect of alcohol consumption on employment probability. In the study we focus attention on woman's absenteeism and the results for men are only reported briefly. The reasons for this are discussed below. 
The study indicates that long-term, light alcohol consumption has a protective effect on the probability of long-term absence, while abstention and heavy drinking have a detrimental effect. However, the detrimental effect is highest for women who have changed their consumption to and from abstention. Hence, controlling for drinking history (and thereby avoiding the former drinking and former abstainer errors) is important. We also find that controlling for the selection effect into employment is important and that a conventional probit model generally understates the effects of alcohol. In a simple model simulating changes in the prevalence of consumption, we find that although alcohol on average only explains a small part of individual long-term absence, the total societal effect is considerable. The results for men are generally insignificant. Next, we address methods and data, followed by the results of the regressions and the simulation model in subsequent sections. The results will then be discussed and some concluding remarks will be shared.

\section{Estimation Method}

To model the effects of alcohol on absenteeism, we use the micro-economic data set described in Section 3 below. The basic idea of the analysis is that alcohol, by causing increased prevalence of certain diseases and injuries (Dave and Kaestner, 2002; Jarl et al., 2009), increases the prevalence of absenteeism. It is expected that the level of consumption is more closely related to absence in the long run, while the pattern (e.g. binge drinking) is more closely related to absence in the short run (Roche et al., 2008). The short-term effects of alcohol (e.g. hangovers) are also thought to increase work absenteeism.

\section{Methodological considerations}

There are three key methodological issues that need to be considered in the modelling. First, there are individuals that, for different reasons, are not employed. Earlier research has 
demonstrated that male abstainers have a reduced probability of employment, which is almost entirely due to abstainers being diagnosed as alcohol dependant (Johansson et al., 2006). Problem drinking has also been found to reduce the probability of employment (Mullahy and Sindelar, 1993; 1996; MacDonald and Shields, 2004), while other studies have found no such relationship (e.g. Feng et al., 2001). In a Russian sample, Tekin (2002) concludes that when controlling for unobserved heterogeneity, alcohol has no effect on employment for men and a small positive effect for women. Although previous studies have produced vastly different results, one hypothesis is that individual health status is a determinant in the employment equation, and that alcohol affects health status. This implies that we might face a selection effect, in other words, absenteeism might not be observed for those with sufficiently detrimental drinking. This is dealt with below by using a Heckman model, where the selection equation is the employment function, a method not previously employed in the alcoholabsence literature.

The second methodological issue is that alcohol affects health over both the short and long term; in other words, drinking history may be as important as current level of alcohol consumption. In addition, changes in alcohol consumption over time may be considered a proxy for (alcohol) problems. Earlier studies have shown that former drinkers who are now abstainers are, in many aspects, different from long-term abstainers (Fillmore et al., 1998). This is also true for other consumption groups such as former abstainers that are now light drinkers and long-term light drinkers (Jarl and Gerdtham, 2010). Failure to control for past consumption may result in biased estimates (Sharper et al., 1988; Jarl and Gerdtham, 2010). It is interesting to note that, with the exception of one study that controls for the former drinker error (Vahtera et al., 2002), no prior studies consider the possibility of bias due to individuals with the same current consumption level faces different outcomes based on their consumption 
history. We address this by constructing alcohol variables that control for drinking history and any possible change (see Section 3 below).

Third, there is an alternate theory for explaining the relationship between alcohol and absenteeism: that absenteeism increases alcohol consumption through, for example, selfmedication or reduced social control when spending time at home (e.g., Aira et al., 2008; Suh et al., 2008). The relationship between alcohol and absenteeism is difficult to disentangle and normally is only association estimated. The alcohol variables in this study, constituting both current and past consumption, can be interpreted as the change in consumption. As this change has taken place in between the waves, the causality is stronger than in most prior studies. However, it can be debated if the time between the change and the observation is long enough to control for reversed causality.

We model the effect of alcohol on the likelihood of an episode of absenteeism using a probit equation:

$\mathrm{y}_{1 \mathrm{i}}=\mathbf{r}_{\mathrm{i}} \beta_{1}+\mathbf{x}_{\mathrm{i}} \beta_{2}+\mathrm{u}$

where $\mathrm{y}_{1}$ is equal to 1 if absent from work for $\mathrm{i}^{\text {th }}$ individual, 0 otherwise, $\mathbf{r}$ is a set of alcohol variables that incorporates both current and past consumption, $\mathbf{x}$ is a set of control variables including health and $u$ is the error term. Our main hypothesis is that $\beta_{1}>0$. If this holds, then productivity losses may be avoided if current and past alcohol consumption could be reduced.

However, information on absenteeism is limited to a sample of the working population. Thus, absence is observed contingent on the likelihood of employment, which may be modelled as: $\mathrm{y}_{2 \mathrm{i}}=\mathbf{r}_{\mathrm{i}} \gamma_{1}+\mathbf{z}_{\mathrm{i}} \gamma_{2}+\mathrm{v}$ 
where $\mathrm{y}_{2}$ is equal to 1 if employed for $\mathrm{i}^{\text {th }}$ individual, 0 otherwise, $\mathbf{z}$ is a set of control variables, and $\mathrm{v}$ is the error term. It may be expected that $\gamma_{1}<0$. If there is a non-zero correlation between $\mathrm{u}(1)$ and $\mathrm{v}(2), \mathrm{E}[\mathrm{u} \mid \mathrm{v}]=\rho \mathrm{v}$, the absenteeism model may be specified as:

$\mathrm{y}_{1 \mathrm{i}}=\mathbf{r}_{\mathrm{i}} \beta_{1}+\mathbf{x}_{\mathrm{i}} \beta_{2}+\rho \mathrm{v}$

Failure to allowance for non-random sampling when estimating (3) results in biased estimations. In this case, $\mathbf{z}$ in equation (2) must be a superset of $\mathbf{x}$ in equation (1) (Baum, 2006; Wooldridge, 2003). We estimate $\beta, \gamma$ and $\rho$ jointly using a full maximum-likelihood procedure (Baum, 2006). For this we use Stata software and the heckprob command (Stata Corp., 2005). We employ robust cluster estimation and to facilitate interpretation, and calculate average marginal effects using the Stata margeff command (Bartus, 2005, version 2.1.8). The possibility of unobserved heterogeneity in the absenteeism model is dealt with by including the health lag.

The estimated model is used to predict the probability of individuals experiencing long-term absenteeism, conditioned on them being both employed and non-employed, but had they been employed. We multiplied the predicted probability with the average number of long-term sick days for those who had at least one long-term spell of absence, which gives the expected number of long-term absence days per individual. By simulating a change in the prevalence of alcohol consumption and re-predicting the probability of absenteeism, we can calculate the difference in number of expected long-term sick days. These prevalence changes can be seen as effective interventions. Four such hypothetical interventions/prevalence changes will be simulated:

- To stop alcohol consumption among heavy drinkers and thereby turn them into former drinkers (short-term simulation); 
- To reduce alcohol consumption among heavy drinkers and thereby turn them into current light but formerly heavy drinkers (short-term simulation);

- To prevent heavy drinkers from becoming heavy drinkers, and thereby turn them into light drinkers (long-term simulation);

- To prevent any individual from ending up in any of the drinking group save the group that is most beneficial based on the results of the model above (long-term simulation).

These simulations indicate the attributable fraction of alcohol on long-term absence, and indicate the maximum productivity gains in value terms from the assumed interventions under different scenarios.

\section{Instruments}

Variables included in $\mathbf{x}$ and $\mathbf{z}$ above are variables that are normally controlled for in estimates of labour market outcomes (see below). In order to identify the Heckman model in practical applications, we need $\mathbf{z}$ to be a superset of $\mathbf{x}$; in other words, $\mathbf{z}$ should include the determinants of $\mathbf{x}$ but also some determinants specific to $\mathbf{z}$, commonly termed instruments.

Unemployment rates affect the probability of being in paid employment. However, it has also been shown that it also affects sickness absence rates. Although some studies have shown this also for Sweden (Knutsson and Goine, 1998; Berggren et al., 2002), the effect is uncertain. A common suggested explanation of the relationship between unemployment and absence rates is that reduced perceived job security that follows from economic slow downs with high unemployment reduces shirking and/or increases presenteeism (working while sick). It has indeed been shown that perceived job security affects sickness absence in Sweden, although this mostly affects short-term absence. Interestingly, there is only a weak effect on long-term absence (measured as longer than 7 days) (Khan and Rehnberg, 2009). Likewise has Olsson 
(2007) shown that a change in the Swedish labour legislation in 2001 that reduced the job security of employees affected short-term much stronger than long-term absence. This is also connected to the issue of moral hazard which is expected to be more related to short-term than long-term absence as a medical certificate is required after the first 7 days. Considering that long-term absence in the current study is measured as longer than 28 days, we argue that the effect of perceived job security is negligible. Another Swedish study investigated the effect of unemployment rates and occupation as predictors for long term sickness absence defined as longer than 29 days (Knutsson and Goine, 1998). They found, when controlling for occupation, no effect of unemployment rates for women and an inversed relationship for men. Interesting to note is that without controlling for occupation, their results showed a positive relationship between unemployment rate and long-term sickness absence for both men and women. A suggested explanation for the gender differences in results is that a greater proportion of women compared to men are employed by public employers that are less sensitive to business cycles (Knutsson and Goine, 1998). Information from comparable, neighbouring countries is conflicting. A study in Norway on one hand showed that increased job insecurity due to increased unemployment reduced long term sickness absence, measured as longer than 15 days (Askildsen et al., 2005). On the other hand did a Finish study of the effect of alcohol consumption on sickness absence show a positive effect of regional unemployment on sickness absence, i.e. increased sickness absence in regions with high unemployment (Johansson et al., 2009). Johansson and Palme (2002), studying policy changes in Sweden 1990-91 that coincided with rising unemployment levels found that it was the increased cost of being on sick leave following policy changes that pulled the absence rates down rather than the increasing unemployment rates. The conclusion for the current study based on prior research is that unemployment rates mainly affects short-term absence and potentially mostly men's sickness absence. Given that the current study investigates long- 
term absence among women (although the results for men also are presented), unemployment rate appears to be an appropriate instrument.

From a legislative perspective, the Swedish labour legislation (LAS 1982:80) strongly protects the employee from unreasonable discharge. Disease, sickness absence or parental leave are not reasonable grounds for dismissal. Even in the extreme cases where the disease makes it impossible for the employee to perform his/her work tasks in the long run, it falls on the employer to, if possible, find other assignments for the employee. The union to which the employee belongs has the same rights to be informed and to act instead of the employee to contest dismissals. All this can also be taken as an additional argument that the employee should not fear discharge due to sickness absence, no matter in what business cycle phase the country currently finds itself.

Two instruments connected to unemployment are tested in the current study, the yearly national unemployment rate and the yearly municipality unemployment rate. The former should capture the business-cycle effect beyond the pure time effect, thus affecting the probability of employment. The latter is expected to also capture differences in employment possibilities beyond the business-cycle effect, such as differences within the country at a certain time point. We will also try to capture this with a third instrument - homogeneous regions. Statistics Sweden divides the country based on municipalities into 7 regions with respect to population basis (Statistics Sweden, 2003), see 3.2 below. The rational behind this instrument is that regions have different supply of potential employers and thus employment possibilities and that this is correlated to the population density. That is, individuals living in for example Stockholm has a much larger supply of employment possibilities than individuals 
living in a rural municipal in Northern Sweden. This should thus affect the probability of employment although not being connected to sickness absence.

The forth instrument that will be employed is whether the individual has any small children. Having a small child is considered to affect the probability of paid employment, especially among women as they take larger responsibility for children compared to men. However, it is not expected to affect the probability of sickness absence as absence due to care of a sick child is registered specifically as "temporary parental benefit". The temporary parental benefit is generally higher than sick pay/benefit why possible moral hazard issues could be expected to reduce sickness absence and increase absence due to a sick child. However, this should mostly affect short-term absence. All four instruments will be tested individually and in different combinations and their appropriateness will be discussed after the results have been presented.

\section{Data}

In terms of compensation, absence in Sweden is divided into two different periods. During the first period, the employee receives sick pay from the employer. In the second period, the employee receives sickness benefits from the Social Insurance Agency. Given this division of responsibility, no national register data exists for sick pay, while data on sickness benefits is of good quality. In this study, therefore, we define long-term absence as absenteeism long enough to be covered by sickness benefits.

\section{Participants}

We apply the model to data from the Swedish Survey of Living Conditions (the ULF survey) from Statistics Sweden, matched to register data from the Longitudinal Integration Database 
for Health Insurance and Labour Market Studies (LISA). Since 1975, Statistics Sweden has conducted annual systematic surveys of living conditions in the form of one-hour personal interviews with randomly selected 16-84 year olds. In this study we used data from 1988/89, 1996/97 and 2004/05, three two-year waves focusing on health-related issues, where the first wave is only used to control for drinking history and lags. The LISA material includes individual-specific information from the Social Insurance Agency, such as sickness benefits. The matching of survey and register data allows us to study the effect of health-related behaviours on actual labour market outcomes.

The working sample constitutes of 6,109 individuals based upon 15,471 observations $(3,253$ individuals are followed over three waves and 2,853 individuals are followed over two waves). Of these, 2,449 are women with 6,144 observations (out of which 1,246 are followed over three waves and 1,203 over two waves). Due to the use of the lag when constructing the alcohol variable, we get 3,695 $\left(1,246^{*} 2+1,203\right)$ observations available for the estimations. We lose 162 observations due to missing alcohol information, leaving a sample of 3,533 observations (2,294 women, out of which 1,239 are followed over three years). We correct for missing values in other variables by using Stata's impute command (StataCorp., 2007) (two missing values for the lag of health, 11 for education, 54 for ever having been obese, and 47 missing values for the lag of income).

\section{Measures}

An individual is considered employed if she works full- or part-time, runs a company or a farm, or works at least one hour per day in a family business/farm. As mentioned above, longterm absenteeism is defined as receiving sickness benefit from the Social Insurance Agency. However, the length of the employer responsibility period has differed over the years. In 1997 
the period was 28 days, in 2004 it was 21 days, and in 1996 and 2005 it was 14 days (Försäkringskassan, 2005); as a result, the register data differs over the years. We have therefore defined long-term absence as absences longer than 28 days, which is the longest employer responsibility period covered by the study. In order for an individual to be categorized as having a long-term absence during a specific year, the individual must be employed and receive sickness benefit for at least one sickness spell longer than 28 days during that year.

We constructed alcohol variables that focus on changes in consumption from the survey data. A question asking whether the respondent had consumed any kind of alcoholic beverage within the previous 12 months was used. In addition, questions on the level of weekly consumption were used to differentiate between low and heavy drinking, using the cut-off points suggested in Rehm et al. (2004). Hazardous and harmful consumption were combined into heavy consumption in order to avoid too few observations in each category. The panel information allowed us to construct six consumption groups based on current and past consumption. Long-term abstainers were defined as abstainers in two following waves: in $1988 / 89$ and 1996/97, or 1996/97 and 2004/05. Former drinkers were defined as alcohol consumers during the first of two following waves and abstainers in the second wave (e.g. consumed in 1988/89 but not in 1996/97). All other consumption categories were defined in the same manner (see Table 1, where the proportions of observations for each consumption group also are shown). Measurement errors in the reporting of alcohol consumption are normally expected for several reasons, such as recall bias and fear of stigmatisation. The alcohol variable created in the current study is considered to reduce the negative effect of measurement errors, as it measures considerable changes (or non-changes) in consumption. 
Although the exact level is expected to be measured with a bias, the change from, for example, consumption to abstention is considered to be more reliable.

$<<$ Table $1>>$

The income variable is the lag of disposable income. It is converted to US dollars using the average monthly exchange rate for 2005 (SEK 7.47 for US \$1). The prices were adjusted using the Swedish consumer price index (CPI) before conversion. Two variables were created to capture if the individual has smoked or been obese in the current wave or the lag.

The instrument variable homogeneous regions divides Sweden into 7 regions based on population. The three largest cities with surroundings are there own regions, one region is municipalities with more than 90,000 inhabitants within 30 kilometres from the municipalities centre. The fifth region is municipalities with 27-90,000 inhabitants within 30 kilometres from the municipality centre and 300,000 inhabitants within 100 kilometres. The sixth region is the same as the fifth but with less than 300,000 inhabitants. The last region used is for municipalities with less than 27,000 inhabitants within 30 kilometres (Statistics Sweden, 2003).

Most of the observations in the sample are long-term light drinkers while about 5-7\% are found in each of the other alcohol consumption groups. A total of $84 \%$ of the sample is in good health, and about $13 \%$ of those employed have had a spell of long-term absenteeism (see Table 2).

$<<$ Table $2>>$ 
Being employed is most common among current light drinkers (both long-term and formerly heavy drinkers), as seen in Table 3. The lowest employment rate is found among current abstainers, and former drinkers have somewhat lower rates than long-term abstainers. Based on these averages, we would expect negative associations on employment probability from being an abstainer compared to light drinkers, as has been seen in some earlier research (e.g., Johansson et al., 2006). In examining the rate of long-term absenteeism for different alcohol consumption groups, we see that the lowest rates are found among long-term abstainers and long-term light drinkers. Former drinkers and former abstainers show the highest proportion of absenteeism. We would therefore expect that the latter two consumption groups show a positive association with absenteeism, compared to long-term light drinking, while no association is expected for long-term abstention.

$<<$ Table $3>>$

\section{Estimation Results}

This section reports the results of the estimations of probability of employment and long-term absenteeism. We demonstrate the results of the conventional probit estimations first, followed by the sample selection model. Estimates are considered significant at the $5 \%$ level.

\section{Estimating the model without taking selection into account}

The female probit model for having at least one spell of long-term absence shows few significant estimates (see Table 4). Only former drinkers and former abstainers are significant of the alcohol consumption groups, increasing their probability of long-term absenteeism. Neither long-term abstention nor heavy drinking affects absenteeism, compared to long-term 
light drinking. The lag of health demonstrates that being in poor health is not significant, while being in between good and poor health increases the probability of long-term absenteeism. Higher education indicates some protective effect and having ever been obese shows detrimental effects.

\section{Estimating the selection into employment}

Estimating the probability of being employed using a probit model results in a number of significant variables. All consumption groups are related to a decrease in employment probability for women - with the exception of the insignificant group of current light but formerly heavy drinkers - compared to long-term light drinkers (see Table 4). Wald tests show no differences between the different significant alcohol consumption groups. Other variables are as expected: age has an inversed U-shape, the lag of not being in good health reduces employment probability, and more education increases employment probability. Both the lag of unemployment and the national unemployment rate have negative effects with current employment probability, although the effect of the former is much stronger. The variable for ever having been obese has a negative relationship with employment probability.

$<<$ Table $4>>$

\section{Estimating the Heckman selection model}

Empirical testing has indicated that there are several combinations of instruments that appear to work well. Here we will present the result using national unemployment rate and the presences of a small child although other working combinations affect the estimates only marginally. The results changes dramatically when applying the sample selection model of long-term absenteeism where the selection equation is the employment probability model 
The average marginal effects of the selection model for women are shown in Table 5; this is the average of the marginal effects calculated for each individual in the sample. Of all the alcohol consumption groups, being a former drinker increases the probability of long-term absence the most $(18 \%)$ compared to long-term light drinkers, followed by former abstainers (15\%). Long-term abstainers and long-term heavy drinkers have about the same probability of absenteeism (10\%) given employment. The variables for ever having smoked and been obese increases the probability of long-term absenteeism of around 4 and $9 \%$ respectively.

$<<$ Table $5>>$

There are few observations in many of the alcohol consumption groups for men who have at least one spell of long-term absence, ${ }^{3}$ resulting in estimations that are sensitive to the data and estimation methods. The alcohol consumption groups show no relationship to long-term

\footnotetext{
${ }^{2}$ Theoretical secondary school is in preparation for university studies as opposed to practical secondary school that is more focused on professional education.

${ }^{3}$ The reason for this is unknown. One hypothesis is that men's life situation affects their alcohol consumption to a smaller extent then women's, and vice versa.
} 
absenteeism, neither in probit nor sample selection models which could be due to the instruments being more appropriate for women. The lag of health and whether the individual ever smoked or was obese are significant in the selection model, with expected signs. Compared to long-term light drinkers, former drinkers, former abstainers and current light but formerly heavy drinkers are less likely to be employed. Age, the lag of health, smoking and the two variables for unemployment are also significant in the employment equation, with expected signs.

\section{Simulation of productivity gains in terms of reduced sickness absenteeism}

Given the estimations for women in the former section, it is interesting to predict and simulate the effect of assumed consumption changes on long-term absenteeism. The average probability of having at least one spell of long-term absence given employment is 0.135 . The average predicted probability of one spell of long-term sickness for the non-employed subsample, had they been working, is 0.256 . Table $6 \mathrm{a}$ and $6 \mathrm{~b}$ outline the predictions following assumed population interventions (consumption changes). All average changes in expected long-term sick days between the original sample and after the assumed intervention are rather small—generally less than one day. However, considering the large population groups, the net societal effect is considerable, ranging between an increase in long-term sickness of 3'957 productive working years to a decrease of 7’000 years annually. The last row in Table 6 shows the potential productivity change in monetary terms, using the Human Capital Approach. This gives a range from a productivity loss of 798 million SEK to a gain of 1'412 million annually, for the employed population.

$<<$ Table $6 \mathrm{a}+\mathrm{b}>>$ 


\section{Discussion}

The focus of this article has been to analyse the effect of alcohol consumption on sickness absence. The results of the employment probability estimation indicate quite strong relationship between alcohol and employment. Compared to long-term light consumption, all other groups (except current light but formerly heavy consumption) have a negative effect on employment. There is no significant difference between long-term abstainers and former drinkers. Therefore, individuals who have regular, light alcohol consumption seem to have an advantage on the labour market when it comes to the probability of being employed. It is quite surprising that the negative effects on employment from the other alcohol consumption groups are about the same magnitude with variation in point estimates between $11 \%$ and $16 \%$ (average marginal effect). All other variables have expected signs, although it should be noted that the variable for ever having smoked is not significant.

The probit model for long-term absenteeism reveal some remarkable results as, for example, only former drinkers and former abstainers have a positive relationship with absenteeism and age is insignificant. These results are in line with what would be expected following results observed by Jarl and Gerdtham (2010) and Filmore et al. (1998) - that both former drinkers and former abstainers appear to be at a greater disadvantage than long-term abstainers and long-term light drinkers. The effect of health and education are along the lines of the Feng et al. (2001) study.

The results of the effect of alcohol on long-term absenteeism change drastically when we control for selection into employment. When doing so, all consumption groups except current light but formerly heavy drinkers show a significant positive effect on long-term absenteeism compared to long-term light drinkers. There is, however, no statistical difference between the 
effects when using Wald tests. Being a former abstainer, which is commonly defined in studies as a light drinker, increases the risk of long-term absenteeism by close to $15 \%$. Had we failed to separate this group from long-term light drinkers in this study (i.e., conducting the "former abstainer error"), the protective effect of long-term light drinkers would have been smaller. Thus, the increased risk of other alcohol consumption groups would also have been smaller, underestimating the negative outcome of non-regular non-light consumption.

It is also interesting to note that the increased risk of long-term absenteeism is larger for former drinkers $(18 \%)$ than for long-term abstainers (11\%). Failure to separate these two groups is known as the "former drinker error" and would result in an estimate of a 14\% (not shown) probability reduction. That is, underestimating the risk from being a former drinker and overestimating the risk of being a long-term abstainer, in comparison to being a long-term light drinker.

As such, the result from the selection model indicates that long-term light alcohol consumption reduces the probability of long-term absenteeism. Given employment, being a long-term abstainer or heavy drinker increases the risk of absenteeism by around $10 \%$. Having changed consumption behaviour to or from abstention shows the highest increases in risk of long-term absenteeism.

Empirical testing, as mentioned above, showed different working combinations of instruments. Which of these combinations is used only affect the results marginally. The presented results are the estimations with yearly national unemployment rate and having a small child as instruments. The unemployment rate is a predictor of selection but insignificant in the absenteeism equation while having a small child does approach significance. The latter 
is however included due to its theoretical validity although unemployment rate works on its own. Unemployment on a municipality level could be used instead of on a national level (significant at the 10\% level), although it requires controlling for both having a small child and population homogeneous regions.

The most important instrument in these regressions is thus unemployment, either on a national or municipal level. It has been shown in prior research that business-cycle and unemployment rates are connected to absence rates, i.e. when unemployment increases absence rates decreases (Berggren et al., 2002; Askildsen et al., 2005). This is normally explained by insecurity regarding possible dismissal. The empirical testing done within the current study showed that unemployment rate is not connected to probability of long term absence for women in Sweden, when controlling for selection effects into employment. One reason for this might be the strong legal protection towards unreasonable dismissal (which dismissal due to sick leave is considered to be) and the strong positions of the unions. However, this result was not unexpected based on prior studies showing that the effect of unemployment on sickness absence mainly targets short-term absence (Khan and Rehnberg, 2009). In addition, women's long-term absence has been shown in a Swedish study not to be affected by unemployment rates (Knutsson and Goine, 1998). With regard to the results of prior studies, it might not be odd that the results for men turned out as they did in the current study. It is likely that the employed instruments are most appropriate for Swedish women and that other instruments are needed in order to study the effect of alcohol consumption on long-term absence for Swedish men.

As we have discussed above, applying a sample selection model instead of a probit changes the results with stronger and more significant associations in the sample selection model. We 
interpret this as that the probit model underestimates the probabilities of absenteeism due to the fact that non-employed who are sick are not absent. For example, the lag of being in poor health is not significant in the probit model, but strongly significant in the sample selection model. That is, individuals with a lag of poor health are more likely to be non-employed and thus do not experience absenteeism. When we control for this fact, the lag of poor health becomes important for explaining long-term absenteeism. This is further supported by the significant $\rho$ which indicates that ignoring the selection effect would result in biased and inconsistent estimation of long-term absenteeism (Baum, 2006). The fact that the $\rho$ is negative indicates that employment and long-term absenteeism is negatively related (Henneberger and Sousa-Poza, 1998).

It is interesting to assess the results of this study in relation to the alcohol-wage literature that commonly finds a positive effect of alcohol on wages/earnings. For example, Peters (2004) and van Ours (2004) find a general wage premium from drinking while Lee (2003) and Barrett (2002) find a wage premium from moderate drinking, although none of these studies control for any of the former consumption errors discussed above. We would assume that increased absenteeism affects wages negatively, both directly as sickness benefits are lower than wages, and indirectly through reduced human capital accumulation. Increased long-term absenteeism is probably not enough to explain the reduction in wages/earnings as short-term absenteeism should also influence this. It is also possible (a suggested hypothesis in prior research) that current abstainers miss out on work-related social activities, and are thus "punished" for this by being discriminated against or by being overlooked for promotion opportunities. However, given the results of the current study, increasing the probability of long-term absenteeism in the 10-18\% interval for non-long-term light drinkers, we expect 
absenteeism to play a significant roll in the reduction in pay among abstainers and heavy drinkers, compared to light/moderate drinkers.

The predicted probabilities of at least one long-term sickness spell among the individuals in the sample are higher among the non-employed compared to the full sample. That is, individuals who are not employed are more likely to experience long-term absenteeism had they been working, compared to employed individuals. The simulation model of the effect of changes in the prevalence of alcohol on the number of days of long-term absence show rather substantial effects from a population perspective. We start out by turning all heavy drinkers into former drinkers, as this is the logical step based on the modelling of alcohol consumption, which increases the number of expected absence days per year. If we instead assume an intervention that turns heavy drinkers into light drinkers - thereby making them current light but formerly heavy drinkers - no effect is evident for the estimation conditioned on being employed. For those not employed, had they been working, the intervention would have reduced the average number of expected long-term absence days by one-half day. However, it could be argued that the original groups of former drinkers and current light but formerly heavy drinkers are different from heavy drinkers. The total number of sick days would then be overestimated by applying the $\beta$-coefficient from former drinkers (clfhd) on long-term heavy drinkers. A more pragmatic approach might be to assume an intervention that prevented the development of heavy drinkers and thus making them long-term light drinkers instead, which is done in column 4 of Table 6 . The change per individual is rather small for those that are employed, although for the non-employed, had they been working, the reduction in the average absence is 0.7 days per year. Finally, an intervention that puts the whole population into the most beneficial consumption group (long-term light drinkers) would reduce expected sick days over a year by 0.7 days and 3.0 days, respectively (column 5 of Table 6 ). The 
remaining expected absence days of 12.6 (for those employed) and 22.3 (for the nonemployed had they been working) can be considered to be due to factors other than alcohol, such as other health-related behaviours, health status, income or bad luck. In other words, the effect of alcohol on long-term absenteeism is rather small compared to the combined effect of all other factors. However, if the entire female population were long-term light consumers, expected days lost per year due to long-term sickness would be reduced by 1.4 and 0.5 million days for employed and non-employed respectively. This is a substantial societal effect that translates into a productivity loss of SEK 1.4 and 0.5 billion in 2005 (US\$189 and $\$ 67$ million), using the Human Capital Approach. It should also be noted that the alcohol effect is much larger for the non-employed than the employed, giving reason to assume that alcoholrelated problems are more common in this group and that there is a selection effect from alcohol into (non-)employment. All estimates following the simulation are changes during a one year period in order to be comparable with other estimates (e.g. Jarl et al., 2008).

Obviously are the societal productivity gain much higher measured over a person's life-cycle, and the gains are expected to differ at different periods of life. ${ }^{4}$

The discussion above assumes a causal effect between alcohol and being non-employed, and it therefore seems intuitive that societal production could be increased by changes in the prevalence of consumption. However, since the natural rate of unemployment is considered to be larger than zero, the full hypothetical productivity gain among the non-employed, had they been working, could not be realized in actual productivity. The important question is to what extent individuals that would have been a part of the natural unemployment rate replace individuals that leave employment due to alcohol. In any case, friction costs are expected to occur due to the recruitment and training costs involved in replacing an employee

\footnotetext{
${ }^{4}$ This could be estimated by taking into account age effects on the probability of absence and age-adjusted average number of days absent, plus income.
} 
(Koopmanschap et al., 1995). This is also the case for replacing employees due to long-term absenteeism.

There are some limitations to this study. Although we have a rather large data set, the coding of the alcohol variable to account for prior consumption reduces the sample size considerably. Defining long-term absence as longer than 28 days reduces the variation for each consumption group, which might be reflected in some insignificant estimates. Future studies should investigate the effects of alcohol on short-term absenteeism, something we did not do in the current study, although that would require other instruments. Due to data limitations, we were unable to account for patterns of consumption. This is unfortunate, as it has been shown that the pattern of consumption — especially so-called binge drinking — affects outcomes (Rehm et al., 2004). Future studies should endeavour to include consumption patterns.

\section{Conclusions}

This study again demonstrates the importance of avoiding the "former drinker error" and the "former abstainer error" as defined in Jarl and Gerdtham (2010). Divergence from the most prevalent group of long-term light consumers increases the risk of long-term absenteeism among women in Sweden when we control for the selection into employment. Controlling for sample selection, and thus the non-independence of the error terms in the two equations, are important. It is shown that the probability of long-term absenteeism is higher among nonemployed, had they been working, compared to employed. A normal probit model cannot be considered as consistently estimated and generally understates the effects of alcohol on longterm absenteeism. The models for predicting expected long-term sick days per individual 
show that although the effect of alcohol is rather marginal on an average individual basis, it has a large effect on society.

The commonly seen result of the protective effect of regular light consumption and the detrimental effect of abstention and heavy drinking is repeated in the current study, despite efforts to account for drinking history and selection effects. These results are along the lines of earlier studies such as Vahtera et al. (2002) and, regarding current abstainers, as reported in Hensing and Wahlström (2004). Applying a larger sample in future research should be prioritized in order to statistically differentiate the detrimental effects between consumption groups as well as to incorporate patterns of consumption in the estimations.

\section{Conflict of interest}

The authors declare that they have no competing interests.

\section{Acknowledgement}

Financial support from the Swedish Council for Working Life and Social Research (dnr 2006$1660)$ is gratefully acknowledged. 


\section{References}

Aira, M., Hartikainen, S. \& Sulkava, R. 2008 "Drinking alcohol for medicinal purposes by people aged over 75: A community-based interview study" Family practice, 25: 445449

Andréasson, S. 1998 “Alcohol and J-shaped curves, Alcoholism: Clinical and experimental research, 22: 359s-364s

Askildsen, J. E., Bratberg, E. \& Nilsen, Ø. A. (2005) "Unemployment, labor force composition and sickness absence: a panel data study" Health Economics 14: 10871101.

Barmby, T., Ercolani, M. \& Treble, J. (2004) "Sickness absence in the UK 1984-2002" Swedish Economic Policy Review, 11: 65-88

Barrett, G. F. (2002) "The effect of alcohol consumption on earnings" Economic Record, 78: 79-96

Bartus, T. 2005 "Estimation of marginal effects using margeff” Stata journal 5: 309-329

Baum, C. F. (2006) An introduction to modern econometrics using Stata, Stata Press, College Station, TX, USA

Berggren, S., Cohen Birman, M., Nyberg, K., Palmer, E., Skogman Thoursie, P. \& Söderberg, J. (2002) Swedish sickness absenteeism in a European perspective [Svensk sjukfrånvaro i ett erupoeiskt perspektiv] The National Insurance Board Report 2002:11, Stockholm.

Christensen, K. B., Lund, T., Labriola, M., Bültmann, U. \& Villadsen, E. 2007 "The impact of health behaviour on long-term sickness absence: Results from DWECS/DREAM" Industrial health, 45: 348-351

Cunradi, C. B., Greiner, B. A., Ragland, D. R. \& Fisher, J. 2005 "Alcohol, stress-related factors, and short-term absenteeism among urban transit operators" Journal of urban health, 82: 43-57

Dave, D., \& Kaestner, R. (2002) "Alcohol taxes and labor market outcomes" Journal of Health Economics, 21: 357-371

Feng, W., Zhou, W., Butler, J. S., Booth, B. M. \& French, M. T. (2001) "The impact of problem drinking on employment" Health Economics, 10: 509-521

Fillmore, K. M., Golding, J. M., Graves, K. L., Kniep, S., Leino, E. V., Romelsjö, A., Shoemaker, C., Ager, C. R., Allebeck, P., \& Ferrer, H. P. (1998) "Alcohol consumption and mortality. I. Characteristics of drinking groups" Addiction, 93: 183-203

Försäkringskassan [The Social Insurance Agency] 2005 "Sjukfrånvaron in Sverige i ett Europeiskt perspektiv 1983-2004" Redovisar 2005:6 (http://forsakringskassan.se/filer/publikationer/pdf/red0506.pdf)

Henneberger, F. \& Sousa-Poza, A. (1998) "Estimating wage functions and wage discrimination using data from the 1995 Swiss labour force survey: a double-selectivity approach" International Journal of Manpower, 19: 486-506

Hensing, G. and Wahlström, R. (2004) "Chapter 7: Sickness absence and psychiatric disorders" Scandinavian Journal of Public Health, 32: 152-180

HSE 2004 "Managing sickness absence in the public sector" Health and Safety Executive (http://www.hse.gov.uk/gse/sickness.pdf)

Jarl, J., Johansson, P., Eriksson, A., Eriksson, M., Gerdtham, U-G., Hemström, Ö., Hradilova Selin, K., Lenke, L., Ramstedt, M. \& Room, R. (2008) "The societal cost of alcohol consumption: an estimation of the economic and human cost including health effects in Sweden, 2002" European Journal of Health Economics, 9: 351-360.

Jarl, J., Gerdtham, U-G. \& Hradilova Selin, K. (2009) "Medical net cost of low alcohol consumption: A cause to reconsider improved health as the link between alcohol and wage? Cost Effectiveness and Resource Allocation 7:17. 
Jarl, J. \& Gerdtham, U-G. (2010) "Wage penalty of abstinence and wage premium of drinking: A misclassification bias due to pooling of drinking groups?" Addiction Research and Theory, early publication online (http://informahealthcare.com/art).

Johansson, E., Alho, H., Kiiskinen, U. \& Poikolainen, K. (2006) "Abstaining from alcohol and labour market underperformance: Have we forgotten the 'dry' alcoholics?" Alcohol \& Alcoholism, 41: 574-579

Johansson, E., Böckerman, P. \& Uutela, A. (2009) "Alcohol consumption and sickness absence: Evidence from micro data" European Journal of Public Health, 19: 19-22

Johansson, P. \& Palme, M. (2002) "Assessing the effect of public policy on worker absenteeism" Journal of Human Resources 37:382-409.

Johansson, P. \& Palme, M. (2005) "Moral hazard and sickness insurance" Journal of Public Economics, 89: 1879-1890

Khan, J. \& Rehnberg, C. (2009) "Perceived job security and sickness absence: a study on moral hazard" European Journal of Health Economics 10: 421-428.

Knutsson, A. \& Goine, H. (1998) "Occupation and unemployment rates as predictors of long term sickness absence in two Swedish counties" Social Science and Medicine 47: 25-31.

Koopmanschap, M. A., Rutten, F. F. H., van Ineveld, B. M. \& van Roijen, L. (1995) "The friction cost method for measuring indirect costs of disease" Journal of Health Economics, 14: 171-89

Lee, Y. L. (2003) "Wage effects of drinking in Australia" Australian Economic Review, 36: 265-282

MacDonald, Z. \& Shields, M. A. (2004) "Does problem drinking affect employment? Evidence from England" Health Economics, 13: 139-155

McFarlin, S. K. \& Fals-Stewart, W. (2002) "Workplace absenteeism and alcohol use: A sequential analysis Psychology of Addictive Behaviors, 16: 17-21

Mullahy, J. \& Sindelar, J. L. (1993) "Alcoholism, work, and income" Journal of Labor Economics, 11: 494-520

Mullahy, J. \& Sindelar, J. (1996) "Employment, unemployment, and problem drinking" Journal of Health Economics, 15: 409-434

Nordtröm, T. 2006 "Per capita alcohol consumption and sickness absence" Addiction, 101: $1421-1427$

Norström, T. \& Synnøve Moan, I. (2009) "Per capita alcohol consumption and sickness absence in Norway" European Journal of Public Health, advance access 090415

OECD, 2008 OECD employment outlook 2008 - statistical annex OECD, (http://www.oecd.org/dataoecd/54/57/40846335.pdf)

Olsson, M. (2007) “Ökar anställningsskyddet sjukfrånvaron?" [Does employment protection increase sickness absence?] Ekonomisk Debatt 2: 31-41.

van Ours, J. C. (2004) “A pint a day raises a man's pay; but smoking blows that gain away" Journal of Health Economics, 23: 863-886

Peters, B. L. (2004) "Is there a wage bonus from drinking? Unobserved heterogeneity examined" Applied Economics, 36: 2299-2315

Rehm, J., Room, R., Monteiro, M., Gmel, G., Graham, K., Rehn, N., Sempos, C.T., Frick, U., \& Jernigan, D. (2004) Alcohol use. In: Ezzati, M., Lopez, A.D., Rodgers, A., \& Murray C.J.L., eds. Comparative Quantification of Health Risks: Global and Regional Burden of Disease Attributable to Selected Major Risk Factors. Volume 1. Geneva: World Health Organization, pp 959-1108

Roche, A. M., Pidd, K., Berry, J. G. \& Harrison, J. E. 2008 "Workers' drinking patterns: the impact on absenteeism in the Australian work-place" Addiction, 103: 738-748

Shaper, A. G., Wannamethee, G., \& Walker, M. (1988) "Alcohol and mortality in British men: explaining the U-shaped curve" Lancet, 2: 1267-1273 
StataCorp. (2005) Stata Statistical Software: Release 9. College Station, TX, USA

StataCorp. (2007) Data management Stata Press, College Station, TX, USA

Statistics Sweden, 2003 Regionala indelningar i Sverige den 1 januari 2003, del 1 [Regional clasifications in Sweden the 1st of January 2003, part 1] Statistics Sweden, Stockholm (http://www.scb.se/Statistik/OV/OV9999/2003M00/X20OP0301.pdf)

Suh, J. J., Ruffins, S., Robins, C. E., Albanese, M. J. \& Khantzian, E. J. 2008 "Selfmedication hypothesis: connecting affective experience and drug choice" Psychoanalytic psychology, 25: 518-532

Tekin, E. (2002) "Employment, wages, and alcohol consumption in Russia" Southern Economic Journal, 71: 397-417

Tómasson, K., Gunnarsdóttir, H. K., Rafnsdóttir, G. L. \& Helgadóttir, B. (2004) “Correlates of probable alcohol abuse among women working in nursing homes" Scandinavian Journal of Public Health, 32: 47-52

Tüchsen, F., Christensen, K. B. \& Lund, T. (2008) "Shift work and sickness absence" Occupational Medicine, 58: 302-304

Vahtera, J., Poikolainen, K., Kivimäki, M., Ala-Mursula, L. \& Pentti, J. 2002 "Alcohol intake and sickness absence: a curvilinear relation" American journal of epidemiology, 156 : 969-976

Vasse, R. M., Nijhuis, F. J. N. \& Kok, G. (1998) “Associations between work stress, alcohol consumption and sickness absence" Addiction, 93: 231-241

Wooldridge, J. M. (2003) Introductory Econometrics 2nd ed. Mason, Ohio, USA, SouthWestern 
Table 1. Alcohol consumption categories and the proportion of individuals in the employment (absenteeism) estimation

\begin{tabular}{|c|c|c|c|}
\hline Current & Abstain & Low & Heavy \\
\hline Abstain & $\begin{array}{c}\text { Long-term abstainer } \\
6(5) \%\end{array}$ & $\begin{array}{c}\text { Former drinker } \\
5(4) \%\end{array}$ & N/A \\
\hline Low & $\begin{array}{c}\text { Former abstainer } \\
6(5) \%\end{array}$ & $\begin{array}{c}\text { Long-term light } \\
\text { drinker } \\
71(75) \%\end{array}$ & $\begin{array}{c}\text { Current light but } \\
\text { formerly heavy } \\
\text { drinker } \\
5(5) \%\end{array}$ \\
\hline Heavy & N/A & \multicolumn{2}{|c|}{$\begin{array}{c}\text { Long-term heavy drinker } \\
7(6) \%\end{array}$} \\
\hline
\end{tabular}


Table 2. Descriptive statistics, used sample

\begin{tabular}{|l|c|r|r|}
\hline Variable & Definition/explanation & Obs & Mean \\
\hline Employed & =1 if employed & 3533 & 0.742 \\
Long-term absent & 1 if at least one long-term sickness spell & 2621 & 0.128 \\
Long-term abstainer & Long-term abstainer & 3533 & 0.064 \\
Former drinker & Former drinker, current abstainer & 3533 & 0.050 \\
Former abstainer & Former abstainer, current drinker & 3533 & 0.061 \\
Long-term light drinker & Long-term light drinker & 3533 & 0.706 \\
Current light but & Formerly heavy drinker, current light drinker & 3533 & 0.047 \\
formerly heavy drinker & Long-term heavy drinker & 3533 & 0.071 \\
Long-term heavy drinker & Age where 0=24 years of age & 3533 & 20.232 \\
Age0 0 & The square of age0 & 3533 & 1,517 \\
Agesquare0 & Disposable income in US\$ (lag) & 3533 & 17,589 \\
Income lag & Self assessed health good (lag) & 3533 & 0.843 \\
Good health lag & Self & 3533 & 0.131 \\
In-between health lag & Self assessed health poor (lag) & 3533 & 0.026 \\
Poor health lag & No or primary school & 3533 & 0.155 \\
Education 1 & Practical secondary school & 3533 & 0.348 \\
Education 2 & Theoretical secondary school & 3533 & 0.132 \\
Education 3 & Higher education & 3533 & 0.365 \\
Education 4 & Current and/or former smoker & 3533 & 0.317 \\
Eversmoke & Current and/or former obese & 3533 & 0.092 \\
Everobese & Individual unemployment (lag) & 3533 & 0.068 \\
Unemployment lag & National unemployment rate & 3533 & 0.282 \\
Small child & & 3533 & 6.836 \\
unemployment rate & &
\end{tabular}


Table 3. Number of employed women and number with long-term absenteeism

\begin{tabular}{|l|cc|cc|}
\hline & \multicolumn{2}{|c|}{ Employment } & \multicolumn{2}{c|}{ Long-term absence } \\
& No & Yes & No & Yes \\
\hline Long-term abstainer & 99 & 128 & 113 & 15 \\
Percent & 43.61 & 56.39 & 88.28 & 11.72 \\
\hline Former drinker & 81 & 97 & 76 & 21 \\
Percent & 45.51 & 54.49 & 78.35 & 21.65 \\
\hline Former abstainer & 81 & 135 & 110 & 25 \\
Percent & 37.5 & 62.5 & 81.48 & 18.52 \\
\hline Long-term light drinker & 533 & 1,961 & 1,726 & 235 \\
Percent & 21.37 & 78.63 & 88.02 & 11.98 \\
\hline Current light but & 36 & 130 & 111 & 19 \\
formerly heavy drinker & 21.69 & 78.31 & 85.38 & 14.62 \\
Percent & 82 & 170 & 149 & 21 \\
\hline Long-term heavy drinker & 32.54 & 67.46 & 87.65 & 12.35 \\
Percent & 912 & 2,621 & 2,285 & 336 \\
\hline Total & 25.81 & 74.19 & 87.18 & 12.82 \\
\hline Percent & & & &
\end{tabular}


Table 4. Probability of long-term absence among women

\begin{tabular}{|c|c|c|c|c|}
\hline \multirow[b]{3}{*}{ Long-term abstainer } & \multicolumn{2}{|l|}{ Probit } & \multicolumn{2}{|c|}{ Heckprob } \\
\hline & \multicolumn{4}{|c|}{ Long-term sickness } \\
\hline & -0.121 & & 0.279 & $* * *$ \\
\hline Former drinker & 0.330 & ** & 0.477 & $* * *$ \\
\hline Former abstainer & 0.302 & ** & 0.384 & $* * *$ \\
\hline $\begin{array}{l}\text { Current light but } \\
\text { formerly heavy drinker }\end{array}$ & 0.125 & & 0.080 & \\
\hline Long-term heavy drinker & 0.025 & & 0.260 & $* * *$ \\
\hline Age0 & -0.002 & & -0.178 & $* * *$ \\
\hline Agesquare 0 & 0.000 & & 0.002 & $* * *$ \\
\hline Income lag & $4.16 \mathrm{E}-06$ & & $-2.50 \mathrm{E}-06$ & \\
\hline In-between health lag & 0.470 & $* * *$ & 0.464 & $* * *$ \\
\hline Poor health lag & 0.479 & * & 0.996 & $* * *$ \\
\hline Education 2 & -0.098 & & -0.275 & $* * *$ \\
\hline Education 3 & -0.308 & ** & -0.505 & $* * *$ \\
\hline Education 4 & -0.230 & ** & -0.416 & $* * *$ \\
\hline Eversmoke & 0.089 & & 0.106 & $* *$ \\
\hline Everobese & 0.256 & ** & 0.249 & $* * *$ \\
\hline Unemployment lag & 0.077 & & 0.290 & $* * *$ \\
\hline \multirow[t]{2}{*}{ Constant } & -1.276 & $* * *$ & 0.194 & $*$ \\
\hline & \multicolumn{4}{|c|}{ Employment } \\
\hline Long-term abstainer & -0.414 & $* * *$ & -0.410 & $* * *$ \\
\hline Former drinker & -0.461 & $* * *$ & -0.466 & $* * *$ \\
\hline Former abstainer & -0.334 & $* * *$ & -0.335 & $* * *$ \\
\hline $\begin{array}{l}\text { Current light but } \\
\text { formerly heavy drinker }\end{array}$ & -0.086 & & -0.087 & \\
\hline Long-term heavy drinker & -0.324 & $* * *$ & -0.323 & $* * *$ \\
\hline Age0 & 0.240 & $* * *$ & 0.244 & $* * *$ \\
\hline Agesquare 0 & -0.003 & $* * *$ & -0.003 & $* * *$ \\
\hline Income lag & $6.31 \mathrm{E}-06$ & * & $6.60 \mathrm{E}-06$ & * \\
\hline In-between health lag & -0.332 & $* * *$ & -0.341 & $* * *$ \\
\hline Poor health lag & -1.046 & $* * *$ & -1.072 & $* * *$ \\
\hline Education 2 & 0.294 & $* * *$ & 0.302 & $* * *$ \\
\hline Education 3 & 0.463 & $* * *$ & 0.484 & $* * *$ \\
\hline Education 4 & 0.385 & $* * *$ & 0.374 & $* * *$ \\
\hline Eversmoke & -0.090 & & -0.096 & $*$ \\
\hline Everobese & -0.191 & $* *$ & -0.191 & $* *$ \\
\hline Unemployment lag & -0.402 & $* * *$ & -0.420 & $* * *$ \\
\hline Small child & -0.001 & & -0.016 & \\
\hline Unemployment rate & -0.055 & $* * *$ & -0.050 & $* * *$ \\
\hline Constant & 0.237 & & 0.194 & \\
\hline Rho & & & -0.990 & $* * *$ \\
\hline
\end{tabular}

Significance is shown on $1\left({ }^{* * *}\right), 5(* *)$, and $10\left(^{*}\right)$ per cent levels. 
Table 5. Average marginal effects of the probability of long-term absence among women

\begin{tabular}{|c|c|c|}
\hline & \multicolumn{2}{|c|}{$\begin{array}{l}\text { Long-term } \\
\text { sickness }\end{array}$} \\
\hline Long-term abstainer & 0.105 & $* *$ \\
\hline Former drinker & 0.181 & $* * *$ \\
\hline Former abstainer & 0.145 & $* * *$ \\
\hline $\begin{array}{l}\text { Current light but } \\
\text { formerly heavy drinker }\end{array}$ & 0.029 & \\
\hline Long-term heavy drinker & 0.098 & $* * *$ \\
\hline Age0 & -0.059 & $* * *$ \\
\hline Agesquare0 & 0.001 & $* * *$ \\
\hline Income lag & -0.000 & \\
\hline In-between health lag & 0.169 & $* * *$ \\
\hline Poor health lag & 0.360 & $* * *$ \\
\hline Education 2 & -0.095 & $* * *$ \\
\hline Education 3 & -0.178 & $* * *$ \\
\hline Education 4 & -0.140 & $* * *$ \\
\hline Eversmoke & 0.039 & $* *$ \\
\hline Everobese & 0.091 & $* * *$ \\
\hline Unemployment lag & 0.109 & $* * *$ \\
\hline & Employm & ent \\
\hline Long-term abstainer & -0.139 & $* * *$ \\
\hline Former drinker & -0.156 & $* * *$ \\
\hline Former abstainer & -0.110 & $* * *$ \\
\hline $\begin{array}{l}\text { Current light but } \\
\text { formerly heavy drinker }\end{array}$ & -0.027 & \\
\hline Long-term heavy drinker & -0.107 & $* * *$ \\
\hline Age0 & 0.066 & $* * *$ \\
\hline Agesquare0 & -0.001 & $* * *$ \\
\hline Income lag & 0.000 & $*$ \\
\hline In-between health lag & -0.103 & $* * *$ \\
\hline Poor health lag & -0.319 & $* * *$ \\
\hline Education 2 & 0.083 & $* * *$ \\
\hline Education 3 & 0.135 & $* * *$ \\
\hline Education 4 & 0.106 & $* * *$ \\
\hline Eversmoke & -0.028 & \\
\hline Everobese & -0.059 & $* *$ \\
\hline Unemployment lag & -0.135 & $* * *$ \\
\hline Small child & 0.000 & \\
\hline Unemployment rate & -0.015 & $* * *$ \\
\hline
\end{tabular}


Table 6a. Simulation of an intervention abolishing heavy drinking, among the employed

\begin{tabular}{|c|c|c|c|c|c|}
\hline & $\begin{array}{c}\text { Original } \\
\text { sample }\end{array}$ & $\begin{array}{c}\text { FD } \\
(\text { lhd }=>\text { fd })\end{array}$ & $\begin{array}{c}\text { CLFHD } \\
\text { (lhd=>clfhd) }\end{array}$ & $\begin{array}{c}\text { LLD } \\
(\text { lhd }=>1 \text { ld })\end{array}$ & $\begin{array}{l}\text { All light } \\
\text { drinkers }\end{array}$ \\
\hline $\begin{array}{l}\text { Probability of } \\
\text { long-term } \\
\text { sickness spell }\end{array}$ & 0.135 & 0.139 & 0.135 & 0.134 & 0.128 \\
\hline $\begin{array}{l}\text { Average sick } \\
\text { days }\end{array}$ & 98.87 & 98.87 & 98.87 & 98.87 & 98.87 \\
\hline $\begin{array}{l}\text { Expected sick } \\
\text { days per } \\
\text { individual }\end{array}$ & 13.35 & 13.74 & 13.35 & 13.25 & 12.66 \\
\hline $\begin{array}{l}\text { Diff (original } \\
\text { vs. change) }\end{array}$ & & $\begin{array}{c}0.39 \\
(2.92 \%)\end{array}$ & $\begin{array}{c}0 \\
(0 \%)\end{array}$ & $\begin{array}{c}-0.1 \\
(-0.75 \%)\end{array}$ & $\begin{array}{c}-0.69 \\
(-5.17 \%)\end{array}$ \\
\hline $\begin{array}{l}\text { Number } \\
\text { employed }\end{array}$ & & $2,038,000$ & $2,038,000$ & $2,038,000$ & $2,038,000$ \\
\hline $\begin{array}{l}\text { Potential days } \\
\text { saved }^{* *}\end{array}$ & & $\begin{array}{c}-794,820 \\
(-3,957 \mathrm{yrs}) \\
\end{array}$ & 0 & $\begin{array}{c}203,800 \\
(1,015 \mathrm{yrs})\end{array}$ & $\begin{array}{c}1,406,220 \\
(7,000 \mathrm{yrs})\end{array}$ \\
\hline $\begin{array}{l}\text { Value of gained } \\
\text { production } \\
\text { (million SEK) }\end{array}$ & & -798.4 & 0 & 204.7 & $1,412.6$ \\
\hline
\end{tabular}

${ }^{*}$ Labour Force Survey, Statistics Sweden (www.scb.se), figures for 2005.

${ }^{* *}$ We use actual yearly working time in 2005 of 1,607 hours for Sweden (OECD, 2008).

${ }^{* * *}$ Based on a monthly average pay for women of SEK $22^{\prime} 100$ and 22 working days per month.

Table $6 \mathrm{~b}$. Simulation of an intervention abolishing heavy drinking, among the unemployed

\begin{tabular}{|l|c|c|c|c|c|}
\hline & $\begin{array}{c}\text { Original } \\
\text { sample }\end{array}$ & $\begin{array}{c}\text { FD } \\
(\mathrm{lhd=}=\mathrm{fd})\end{array}$ & $\begin{array}{c}\text { CLFHD } \\
\text { (lhd=>clfhd) }\end{array}$ & $\begin{array}{c}\text { LLD } \\
\text { (lhd=>lld) }\end{array}$ & $\begin{array}{c}\text { All light } \\
\text { drinkers }\end{array}$ \\
\hline $\begin{array}{l}\text { Probability of } \\
\text { long-term } \\
\text { sickness spell }\end{array}$ & 0.256 & 0.259 & 0.251 & 0.249 & 0.226 \\
\hline $\begin{array}{l}\text { Average } \\
\text { sickdays }\end{array}$ & 98.87 & 98.87 & 98.87 & 98.87 & 98.87 \\
\hline $\begin{array}{l}\text { Expected } \\
\text { sickdays per } \\
\text { individual }\end{array}$ & 25.31 & 25.61 & 24.82 & 24.62 & 22.34 \\
\hline $\begin{array}{l}\text { Diff (original vs } \\
\text { change) }\end{array}$ & & $\begin{array}{c}0.3 \\
(1.19 \%)\end{array}$ & $\begin{array}{c}-0.49 \\
(-1.94 \%)\end{array}$ & $\begin{array}{c}-0.69 \\
(-2.73 \%)\end{array}$ & $\begin{array}{c}-2.97 \\
(-11.73 \%)\end{array}$ \\
\hline $\begin{array}{l}\text { Number } \\
\text { unemployed }\end{array}$ & 167,500 & 167,500 & 167,500 & 167,500 \\
\hline $\begin{array}{l}\text { Potential days } \\
\text { saved }\end{array}$ & & $-50,250$ & 82,075 & $\begin{array}{c}115,575 \\
(575 \mathrm{yrs})\end{array}$ & $\begin{array}{c}497,475 \\
(2,477 \mathrm{yrs})\end{array}$ \\
\hline $\begin{array}{l}\text { Value of gained } \\
\text { production } \\
\text { (million SEK) }\end{array}$ & $(-250 \mathrm{yrs})$ & $-409 \mathrm{yrs})$ & 116.1 & 499.7 \\
\hline
\end{tabular}

${ }^{*}$ Labour Force Survey, Statistics Sweden (www.scb.se), figures for 2005.

${ }^{* *}$ We use actual yearly working time in 2005 of 1,607 hours for Sweden (OECD, 2008).

${ }^{* * *}$ Based on a monthly average pay for women of SEK $22 ' 100$ and 22 working days per month. 